\title{
Bone loss before the clinical onset of rheumatoid arthritis in subjects with anticitrullinated protein antibodies
}

\author{
Arnd Kleyer, ${ }^{1}$ Stephanie Finzel, ${ }^{1}$ Jürgen Rech, ${ }^{1}$ Bernhard Manger, ${ }^{1}$ Manuel Krieter, ${ }^{1}$ \\ Francesca Faustini, ${ }^{1}$ Elisabeth Araujo, ${ }^{1}$ Axel J Hueber, ${ }^{1}$ Ulrike Harre, ${ }^{1}$ Klaus Engelke, $^{2}$ \\ Georg Schett ${ }^{1}$
}

\begin{abstract}
Handling editor Tore K Kvien
${ }^{1}$ Department of Internal

Medicine 3, Rheumatology and

Immunology, University of

Erlangen-Nuremberg, Erlangen,

Germany

${ }^{2}$ Institute of Medical Physics,

University of

Erlangen-Nuremberg, Erlangen, Germany
\end{abstract}

\section{Correspondence to}

Professor G Schett,

Department of Internal

Medicine 3, Rheumatology and Immunology, University of

Erlangen-Nuremberg,

Krankenhausstrasse 12 ,

Erlangen D-91054, Germany;

georg.schett@uk-erlangen.de

AK and SF contributed equally to this paper.

Accepted 24 February 2013 Published Online First 21 March 2013
To cite: Kleyer A, Finzel $S$, Rech J, et al. Ann Rheum Dis 2014;73:854-860.

\section{ABSTRACT}

Objective Anticitrullinated protein antibodies (ACPA) are a major risk factor for bone loss in rheumatoid arthritis (RA). We have recently shown that ACPA directly induce bone loss by stimulating osteoclast differentiation. As ACPA precede the clinical onset of RA by years, we hypothesised that ACPA positive healthy individuals may already show skeletal changes.

Methods We performed a comparative micro-CT analysis of the bone microstructure in the metacarpophalangeal joints of ACPA positive and ACPA negative healthy individuals without clinical signs of arthritis.

Results ACPA positive $(n=15)$ and negative $(n=15)$ healthy individuals were not different in age $(48.2 \pm 4.1$ vs $51.4 \pm 3.8$ years, $p=0.57$ ) or gender (eight women and two men in both groups). Bone mineral density was significantly reduced in ACPA positive individuals (mean \pm SEM $280 \pm 11 \mathrm{mg} / \mathrm{cm}^{3}$ ) compared with controls $(327 \pm 6)$. Bone loss was based on cortical bone changes, with significant $(p=0.044)$ reduction in cortical thickness in the ACPA positive group (mean \pm SEM $0.22 \pm 0.03 \mathrm{~mm}$ ) compared with controls $(0.32 \pm 0.03 \mathrm{~mm})$. Areas of cortical porosity were significantly $(p=0.0005)$ more widespread in ACPA positive (mean \pm SEM 7.4 $\pm 1.4 \%$ ) than in ACPA negative individuals (1.0 $0.3 \%$ ).

Discussion Structural bone damage starts before the clinical onset of arthritis in subjects with ACPA. These findings revise the concept that bone damage is an exclusive consequence of synovitis in patients with RA.

\section{INTRODUCTION}

Rheumatoid arthritis (RA) is characterised by chronic inflammation of the synovial membrane and its systemic consequences. ${ }^{1} 2$ Clinical symptoms such as swelling, pain and stiffness result from synovial inflammation, which precipitates progressive bone loss and cartilage damage in the affected joints. To date, bone damage is considered as the mere consequence of synovial inflammation. Current concepts of bone damage in RA suggest that synovitis promotes the synthesis of proinflammatory cytokines, which facilitate osteoclast activation and enhance bone resorption at specific anatomical sites, such as the metacarpophalangeal joints. $^{3-5}$ Bone damage accumulates during the disease course of RA, if the disease is not adequately controlled by antirheumatic therapy.
Early and more recent clinical observations consistently revealed that local and systemic bone loss is found very early in the RA disease process. This observation is surprising, as synovitis may require some time to destroy bone to an extent which is clinically detectable. Van der Heijde has shown that the majority of patients show radiographic bone erosions during the first years of disease. ${ }^{6}$ Later studies based on radiography, ${ }^{7}$ ultrasound ${ }^{8} 9$ and MR tomography ${ }^{10-13}$ showed consistent evidence of bone erosions a few months after disease onset. In addition, other studies provided evidence for bone erosion, and periarticular and systemic bone loss in patients with recent onset RA. Thus (i) dual energy x-ray absorptiometry investigations have shown a rather high rate of osteopenia in RA patients with only a few weeks of disease duration and no exposure to glucocorticoids $^{14}{ }^{15}$; (ii) similarly, hand bone mineral density (BMD) decreases very early in the disease process of RA and can already be visualised in recent onset $\mathrm{RA}^{16}{ }^{17}$; and finally (iii) bone erosions have been documented in RA patients with only a few weeks of disease duration by radiography, ${ }^{18}{ }^{19}$ ultrasound $^{2021}$ as well as MRI. ${ }^{22}$

These findings raise some doubts as to whether synovitis alone is sufficient to explain bone loss in RA. Alternative concepts of bone loss in RA may consider that autoimmunity precedes the onset of clinical disease by many years. ${ }^{23}$ Anticitrullinated protein antibodies (ACPA) emerge years before the clinical onset of the disease. Thus the syndrome of RA may start long before the onset of the clinical symptoms of disease. Terms like 'pre-RA' ${ }^{24}$ and, on a recent consensus work initiated by the European League Against Rheumatism (EULAR), 'RA at risk', have been created to attribute the fact that autoimmunity related to RA is present long before the onset of the clinical disease. ${ }^{25}$

This concept raises the question of whether individuals with autoantibodies (ie, ACPA) without any signs of inflammation can be considered as healthy. Recent data investigating the synovial membrane of ACPA positive individuals without arthritis have suggested that synovial inflammation is absent in these subjects and at best starts only a few weeks before clinical disease onset. ${ }^{26}$ ACPA, however, may facilitate this transition from autoimmunity to inflammation, as animal data have shown that ACPA facilitate the development of experimental 
arthritis in mice. ${ }^{27}$ Moreover, it may be that other organ systems, such as the lung, lymph nodes and bone marrow, may show subtle changes in ACPA positive individuals even before clinical arthritis has started. Recent data showing intestinal lung changes in subjects with positive ACPA but no signs of arthritis support such a concept. ${ }^{28}$ It is thus tempting to speculate whether bone loss may start even before arthritis starts- that is, when an individual has already experienced a break of immune tolerance against citrullinated self-proteins. Although provocative, such concepts are supported by very recent functional studies on ACPA showing that these antibodies support osteoclastogenesis in humans and can induce bone loss in mice. ${ }^{29}$

To investigate whether ACPA are associated with changes in bone architecture and to test the hypothesis that bone loss may start before the clinical onset of disease, we assessed the bone architecture of individuals with ACPA but no signs of arthritis ('RA at risk').

\section{METHODS}

\section{Subjects}

Fifteen subjects with positive ACPA testing but no concomitant signs of arthritis and no history of arthritis were referred to the Department of Internal Medicine 3 of the University of Erlangen-Nuremberg in 2011 and 2012. Subjects received detailed clinical and laboratory examinations, including joint examination for tenderness or swelling as well as assessment of acute phase reactants (erythrocyte sedimentation rate and $\mathrm{C}$ reactive protein). In addition, we assessed data from 15 randomly selected ACPA negative control individuals with comparable ages and gender from a micro-CT cohort of healthy individuals. The study was performed in accordance with the Declaration of Helsinki. Approval from the local ethics committee and the national radiation protection agency (Bundesamt für Strahlenschutz) and written informed consent were obtained for the study.

\section{Assessment of ACPA}

A positive ACPA test was reconfirmed in our department by standard anti-CCP2 enzyme linked immunosorbent assay (ELISA; Phadia/Thermofisher Scientific, Freiburg, Germany) according to the manufacturer's recommendations. In the control group, ACPA testing was also performed to confirm negative testing. The cut-off for a positive test was 6 units/l. Furthermore, antibodies against antimutated citrullinated vimentin were also tested in this cohort by ELISA (Orgentec, Mainz, Germany) to ensure antibody reactivity to citrullinated vimentin, which has been linked to bone loss previously. ${ }^{29}$

\section{Imaging procedure}

All patients received micro-CT scans ${ }^{30} 31$ of the metacarpophalangeal joints 2-4 of right hand. The micro-CT scans were performed with an XtremeCT scanner (SCANCO medical AG, Brüttisellen, Switzerland) at a resolution of $82 \times 82 \times 82 \mu \mathrm{m}$ voxel size. ${ }^{32} 33$ The scan region was 80 slices distal and a maximum of 253 slices proximal of the upper margin of the metacarpal head 3. Scan time was 5.6-8.4 min per subject, depending on the size of the hand. A single investigator (SF) trained in the technique performed all of the scans.

\section{Data analysis in micro-CT}

In the metacarpal heads $(\mathrm{MCH})$ of the second and third digits, bone density parameters (bone volume per total volume (BV/TV $\%$ ), BMD mg HA/ $/ \mathrm{cm}^{3}$ ), structural parameters (such as trabecular number (Tb.N) $(1 / \mathrm{mm})$, trabecular thickness (Tb.Th) $(\mathrm{mm})$ and trabecular separation $(\mathrm{mm}))$ as well as cortical parameters (cortical thickness $(\mathrm{mm})$ ) were measured using the standard evaluation programme provided by the manufacturer of the micro-CT for the distal radius (V.5.4c). This programme allows automatic evaluation.

In a second step, the micro-CT data were analysed using Osirix (V.4.3.2) for the presence and extent of cortical fenestration, as previously described. ${ }^{30}$ Width and depth of bone erosions were measured with the ruler option implemented in Osirix at the palmar, ulnar, dorsal and radial quadrants of the $\mathrm{MCH}$ and the phalangeal bases of the second and third digitus. Erosions were defined as a break of the juxta-articular cortical bone. All assessments were done by two independent readers (KE and MK), blinded to patient identity and ACPA status of the individuals. Intraobserver reproducibility for all structural bone parameters (KE) was very high (intraclass correlations all $>0.95$ ); interobserver reproducibility ( $\mathrm{KE}$ and $\mathrm{MK}$ ) was also high (intraclass correlations all $>0.90$ ).

\section{Statistics}

The unpaired Student's $t$ test for independent samples was used for comparison of groups. Calculations were done with GraphPad Prism V.5.03. A p value $<0.05$ was considered statistically significant.

\section{RESULTS}

\section{Characteristics of subjects}

We included 15 subjects (11 women, four men) with positive ACPA who had a mean $( \pm S D)$ age of $52.1 \pm 11.3$ years. Positive ACPA testing was a serendipitous finding in all 15 subjects, who received routine clinical checkups, including an extensive laboratory examination, by their private practice physician. Subjects were then referred to our unit because of the positive ACPA result to perform rheumatological examinations. None of the subjects reported musculoskeletal complaints at the time of presentation and none had a history of arthralgia of more than 2 weeks or joint swelling of any duration. Subjects were comparable with an ACPA negative control group of 11 healthy women and four healthy men with a mean $( \pm S D)$ age of $49.1 \pm 11.9$ years $(p=0.48)$ who were part of a cohort of healthy subjects established to define physiological micro-CT values in $\mathrm{MCH}$. Sera of the control group were tested for ACPA to confirm that all of the control subjects were indeed negative for ACPA. All subjects were non-smokers. Four women in the ACPA group and four women in the control group were postmenopausal. None of the subjects were receiving sex hormones, glucocorticoids or other bone active drugs.

There were no signs of tender or swollen joints, and patient reported symptoms on the visual analogue scales for pain and global disease activity were absent. Also, no previous episodes of arthritis were recorded in any of the subjects. Acute phase reactants were normal ( $C$ reactive protein $<5 \mathrm{mg} / \mathrm{l}$, erythrocyte sedimentation rate $<20 \mathrm{~mm} / \mathrm{h}$ ) in all 20 subjects. Mean ACPA level in the ACPA positive group was $228 \pm 53 \mathrm{U} / \mathrm{l}$ and mean antimutated citrullinated vimentin level was 197.52 $\pm 225.17 \mathrm{U} / \mathrm{l}$.

\section{Bone loss in ACPA positive compared with ACPA negative individuals}

Quantitative analysis of the bone micro-architecture of the clinically dominant hand in subjects with ACPA showed significant bone loss compared with age and sex comparable ACPA negative healthy controls. Thus BV/TV, which measures the volume of all skeletal structures at a defined three-dimensional space, was significantly $(p=0.003)$ reduced in ACPA positive 
individuals (mean \pm SEM 17.2 $\pm 0.6 \%$ ) compared with controls $(20.4 \pm 0.4 \%)$ (figure 1A). Similarly, BMD was significantly reduced in ACPA positive individuals (mean \pm SEM $280 \pm 11 \mathrm{mg}$ / $\mathrm{cm}^{3}$ ) compared with controls $\left(327 \pm 6 \mathrm{mg} / \mathrm{cm}^{3}\right)$ (figure $1 \mathrm{~B}$ ). Interestingly, quantitative analysis of trabecular bone parameters, such as Tb.N and Tb.Th, showed no significant differences between ACPA positive and ACPA negative individuals although a trend towards thinner trabeculae was observed in the ACPA positive group (figure $1 \mathrm{C}, \mathrm{D}$ ).

\section{Cortical but not trabecular bone is altered in ACPA positive individuals}

As small peripheral bones are dominated by cortical but not trabecular bone, we considered a potential contribution of cortical bone to the net bone loss in ACPA positive individuals. We therefore analysed cortical bone in ACPA positive and ACPA negative individuals. These analyses revealed a significant $(p=0.044)$ reduction in cortical thickness in the ACPA positive group (mean \pm SEM $0.22 \pm 0.03 \mathrm{~mm}$ ) compared with controls $(0.32 \pm 0.03 \mathrm{~mm}$ ) (figures $2 \mathrm{~A}, 3)$. Moreover, cortical surfaces with very thin and porous cortical bone (cortical fenestration; 'pre-erosions') were significantly $(\mathrm{p}=0.0005)$ more abundant in ACPA positive (mean \pm SEM $7.4 \pm 1.4 \%$ ) than in ACPA negative $(1.0 \pm 0.3 \%$ ) individuals (figures $2 \mathrm{~B}, 3)$. Interestingly, these areas of cortical fenestration were associated with focal changes in the trabecular architecture underneath such lesions (figure 3).

\section{No evidence of 'classical' bone erosions in ACPA positive individuals}

We have previously shown that cortical breaks ('erosions') of more than $2 \mathrm{~mm}$ in width are specifically found in RA patients but not in healthy individuals. Small lesions can also be found in healthy individuals by both $\mathrm{CT}^{30}$ and MRI. ${ }^{34}$ Overall, only five small bone erosions could be identified in each group of subjects, which were all $<2 \mathrm{~mm}$ in size. There was no difference in the mean width of these five erosive lesions among ACPA positive (mean \pm SEM $0.86 \pm 0.11 \mathrm{~mm}$ ) and ACPA negative $(0.74 \pm 0.18 \mathrm{~mm})$ individuals. The distribution of these lesions was very similar among ACPA positive and ACPA negative individuals, with the typical predilection site for erosions at the radial face of the second and third $\mathrm{MCH}$.

\section{DISCUSSION}

This study shows that healthy individuals with an immune response against citrullinated proteins but no signs of arthritis show alterations in cortical bone architecture. ACPA positive individuals exhibited significant changes in periarticular bone resembling thinning and fenestration of the cortical bone as well as milder changes in trabecular bone (figure 4). We believe these findings are remarkable and challenge the concept that bone damage in RA is exclusively caused by inflammation.

In this group of individuals, detection of ACPA had been a serendipitous finding during routine medical consultations. Individuals were referred to the rheumatology department because of ACPA positivity rather than joint complaints. Thus none of these individuals had clinical signs of arthritis, such as joint tenderness or swelling, at the time of presentation, nor did they have a history of such symptoms. It is thus very unlikely that bone changes result from synovitis given that (i) there were no clinical signs of synovitis and (ii) histological studies of the synovium by Van de Sande et al have shown that synovitis emerges immediately, but not a long time, before the clinical onset of RA. ${ }^{26}$ Moreover, acute phase reactants were not elevated in any of these subjects.

Taking into account the fact that (i) several studies ${ }^{6-22}$ have shown a high prevalence of localised bone lesions and osteopenia in recent onset RA patients and (ii) that such patients did not experience long term exposure to inflammation or
Figure 1 Bone loss in subjects with anticitrullinated protein antibodies (ACPA). (A) Bone volume per total volume and $(B)$ bone mineral density at the metacarpal heads in subjects with $(n=10)$ and respective controls without $(n=10)$ ACPA. For assessment of trabecular bone, the number of bony trabeculae (C) as well as trabecular thickness (D) were assessed.
A.
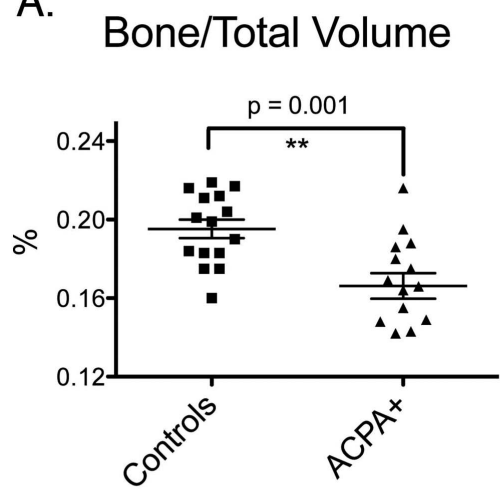

C.
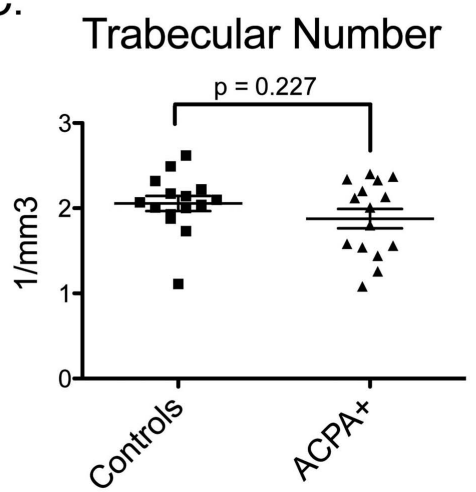

B.

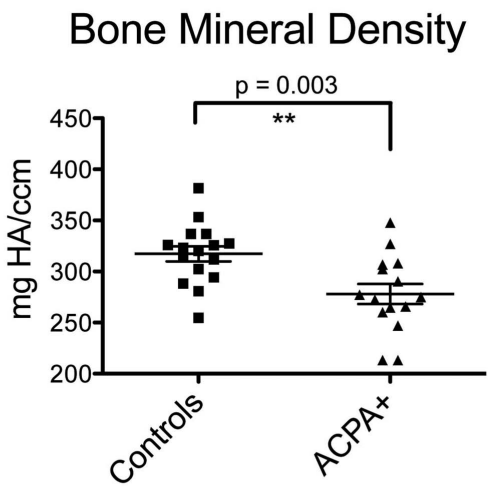

D.
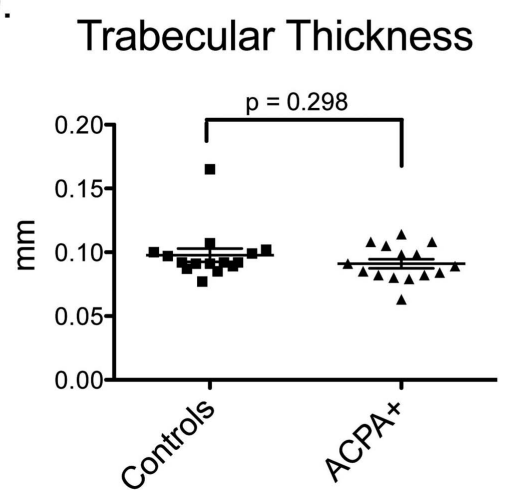
Figure 2 Cortical bone changes in subjects with anticitrullinated protein antibodies (ACPA). (A) Cortical bone thickness and (B) extent of areas of cortical bone fenestration were assessed at the metacarpal heads of subjects with $(n=10)$ and respective controls without $(n=10)$ ACPA. (B) Two examples of areas of cortical fenestration (yellow arrows) in ACPA positive individuals, showing corroded cortical bone in three-dimensional reconstructions of the metacarpophalengeal joint (right). Respective examples of ACPA negative controls showing smooth cortical bone surfaces (left).
A.

\section{Cortical Thickness}
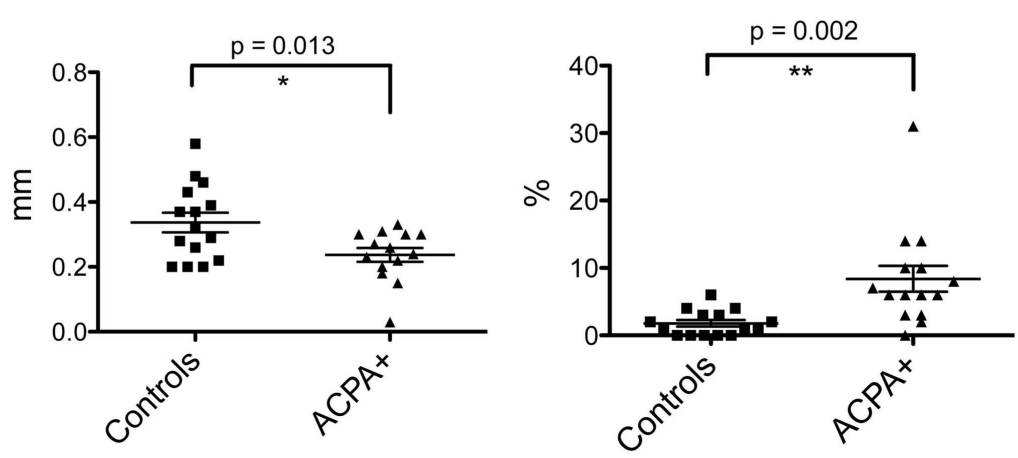

B.
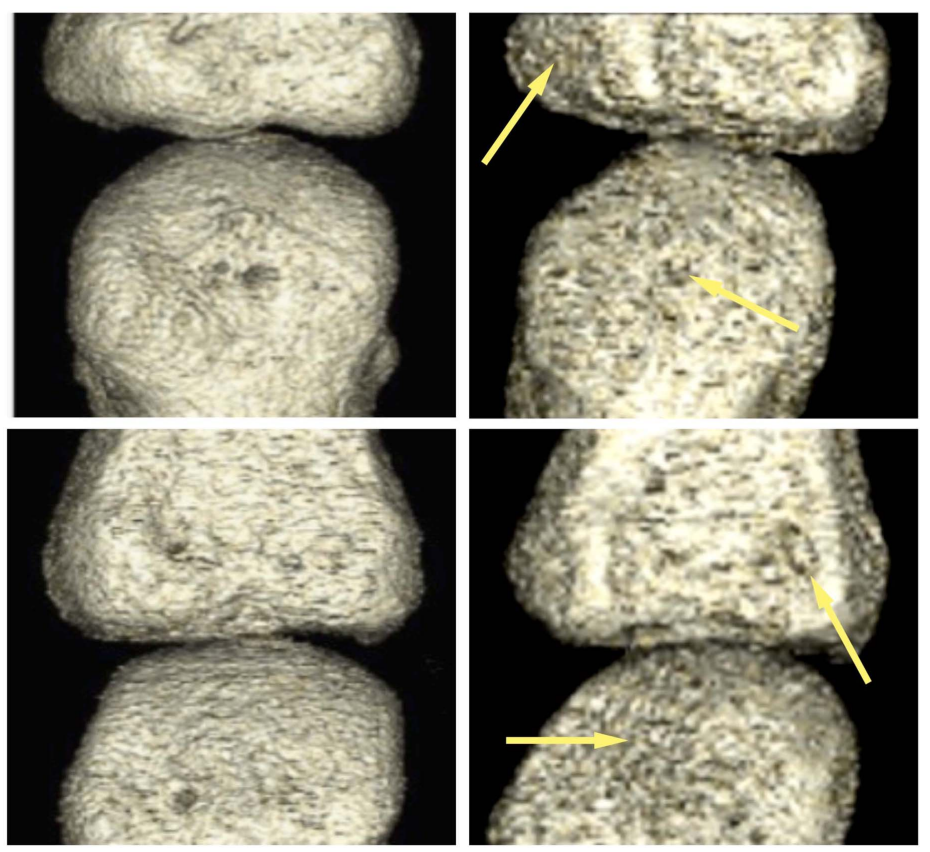

immunosuppressive drug therapy, bone changes in subjects with ACPA may be directly linked to autoimmunity. Indeed, we have recently shown that ACPA can directly contribute to bone loss by stimulating differentiation of bone resorbing cells. ${ }^{29}$ Thus monocytes challenged with purified ACPA from patients with RA showed enhanced differentiation into osteoclasts, suggesting that these autoantibodies directly stimulate bone resorption. This concept was proven in vivo by showing that human ACPA cause bone loss in immune deficient mice, but in vivo proof in humans has so far been lacking. ACPA positive healthy individuals indicate that this concept may be translated to the human situation as autoantibodies are the main precipitating factor for bone loss in these subjects and there is little confounding by inflammatory disease. In support of this notion it is also interesting that a recent study showed alterations in bone biomarkers, such as osteoprotegerin, in subjects before the clinical onset of RA. ${ }^{35}$ ACPA have been shown to cause bone loss through very small increases in tumour necrosis factor $\alpha$ synthesis in osteoclast precursors and we cannot exclude the fact that subclinical inflammation contributes to bone loss before the onset of clinical disease. In fact, previous studies have shown that acute phase reactants ${ }^{36}$ as well as cytokine and chemokine levels ${ }^{37}$ are slightly increased in the preclinical phase of the disease. Furthermore, distinct inflammatory changes have been described in animal models of arthritis starting before the clinical onset of disease. ${ }^{38}$ Also, recent positron emission tomography data in preclinical disease in humans suggest phases of subclinical inflammation in the joints of preclinical RA. ${ }^{39}$ It can be speculated that local plasma cell accumulations, ACPA production and osteoclast recruitment may be associated with such changes.

The observation that the first bone changes are characterised by cortical fenestration providing a direct connection between the bone marrow and the joint is interesting. At present we do not know where the plasma cells producing ACPA are localised. Whereas citrullination of proteins may emerge at sites distant from the joints, like the lung epithelium and gingival mucosa, we do not know where and how the break in immune tolerance occurs and where the first autoimmune plasma cells start production of ACPA. Bone marrow plasma cells may be a potential source for ACPA. Indeed, enrichment of plasma cells in the bone marrow was one of the first recognised pathologies of RA almost 80 years ago. ${ }^{40}$ Later, immune phenotyping of bone marrow infiltrates in RA has shown enrichment of plasma cells along the periarticular cortical bone. ${ }^{41}$ Moreover, MRI studies suggested that bone marrow inflammation (osteitis) is associated with the subsequent destruction of cortical bone. ${ }^{10-12} 42$ Interestingly, changes in cortical bone have been demonstrated to be associated with later development of bone erosions. ${ }^{43}$ One 

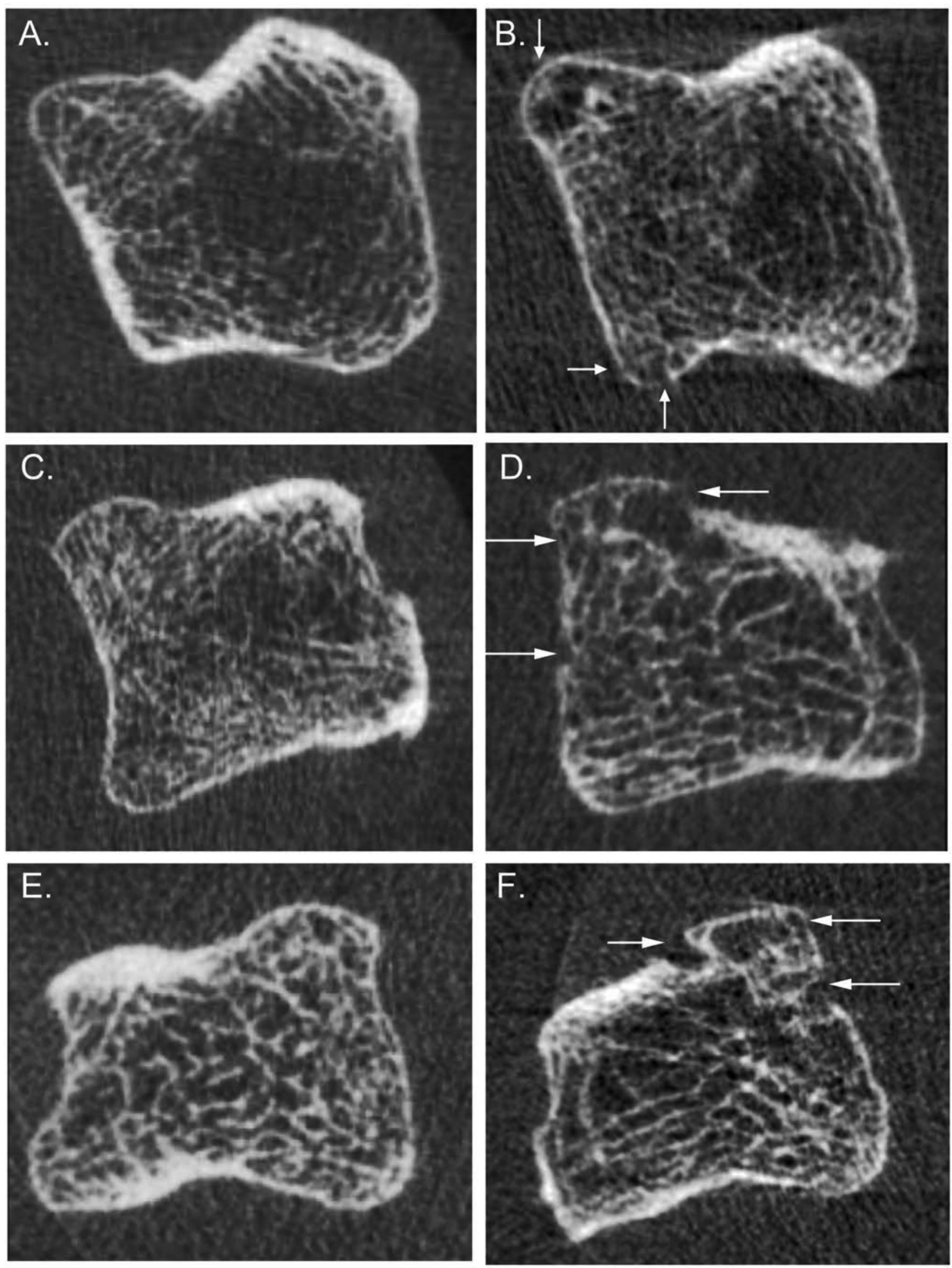

Figure 3 Examples of cortical bone changes in subjects with anticitrullinated protein antibodies (ACPA). Micro-CT images showing the metacarpal heads of three controls without (,$C$ and $E$ ) and three subjects with ACPA (B, D and F). Arrows show cortical thinning, cortical fenestration as well as small bone erosions.

can thus hypothesise that accumulation of bone marrow plasma cells next to cortical bone and along the cortical bone channels could be the source of ACPA, which in turn could lead to bone erosion. In fact, fenestration of the cortical bone may reflect widening of existing small cortical bone channels, which pave the way for blood vessels to the bone marrow cavity. ${ }^{44}$ Several of these observations suggest that inflammatory lesions in RA may affect the bone marrow first rather than the synovial membrane, supporting an inside-out hypothesis of the pathogenesis of RA. ${ }^{45}$ Although not proven, such a concept provides an appealing alternative explanation of how RA affects the joints. Bone marrow plasma cell accumulations producing ACPA may allow widening of cortical bone channels and this process would allow inflammatory cells to easily conquer the joint space, giving rise to synovitis followed by synovial hyperplasia.
How far the classical outside-in hypothesis of RA, with synovitis first and bone erosions and bone marrow involvement later, is challenged by our findings remains to be determined.

In summary, the bone architecture is altered before the clinical onset of RA in subjects with ACPA. This finding is interesting as it further attributes pathogenic relevance to ACPA. The data also raise several interesting questions for further research: (i) it is tempting to speculate whether those subjects with the most severe bone pathology are more prone to develop RA; (ii) it will also be interesting to know whether ACPA positive subjects show cartilage changes. Recent data suggest that bone and cartilage changes in RA can occur independently of each other. ${ }^{46}$ MRI assessment of ACPA positive subjects may provide a tool to assess the articular cartilage in these subjects ${ }^{47}$; finally, (iii) MRI may also be helpful to search for the occurrence of 

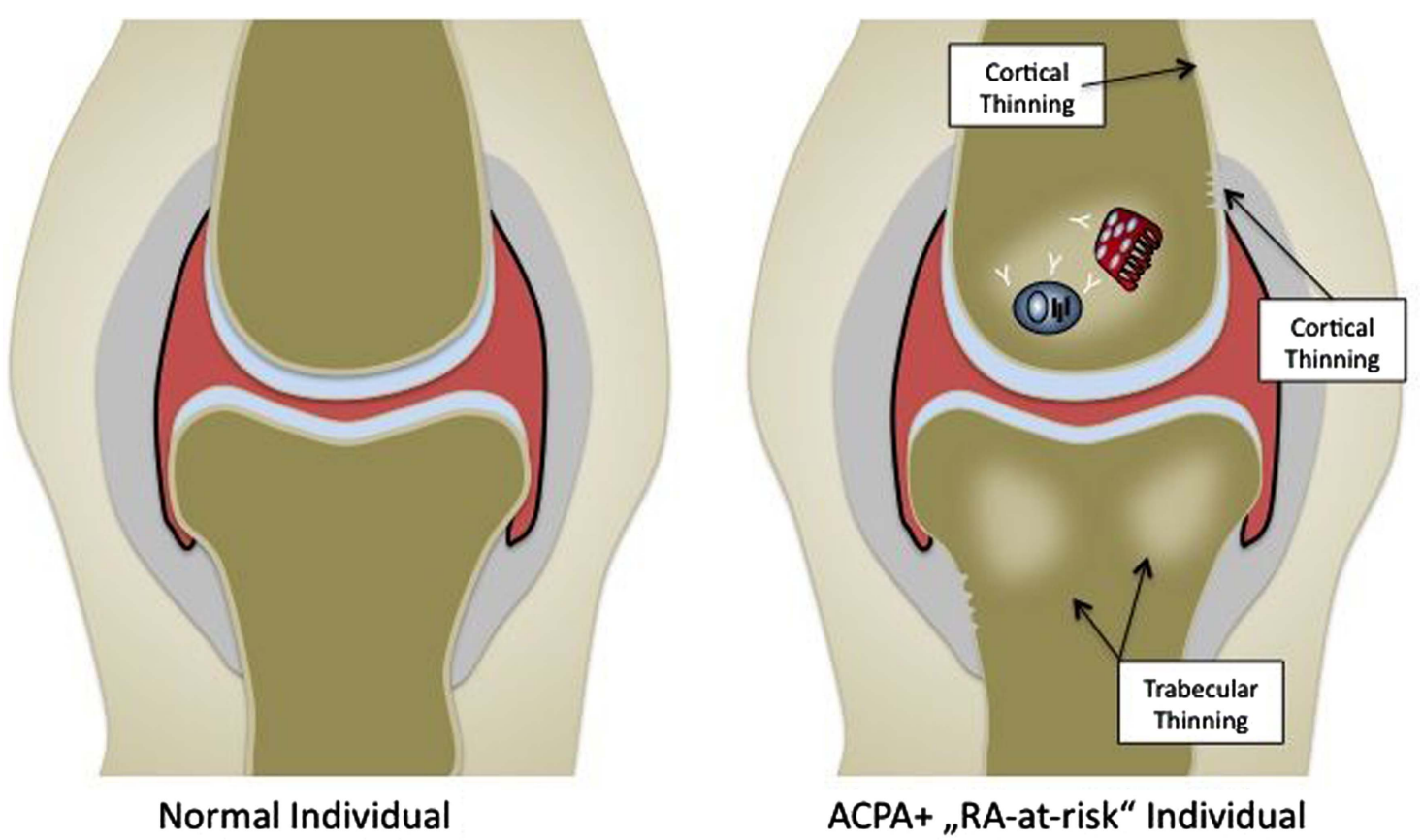

Figure 4 Summary of bone changes in subjects with anticitrullinated protein antibodies (ACPA). In contrast with normal individuals (left), which do not show bone changes except for occasional small erosive changes, subjects with ACPA (right) develop cortical thinning, cortical fenestration and spots of trabecular thinning, leading to an overall decreased bone mass. RA, rheumatoid arthritis.

bone marrow inflammation in ACPA positive subjects and its relation to structural bone changes to further foster the link between osteitis and bone loss. Our data also support a dual hit hypothesis of RA, with an initial break of tolerance and the formation of ACPA, and a second hit translating the autoimmunity

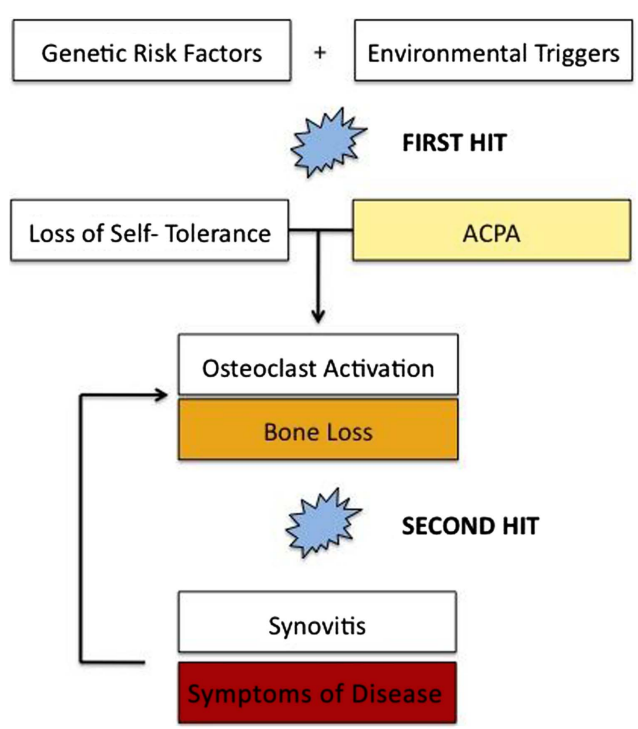

Figure 5 Pathogenic concept of rheumatoid arthritis with bone loss preceding inflammatory disease. Dual hit hypothesis of rheumatoid arthritis, with the first hit representing the break of immune tolerance by a combination of genetic and environmental factors, leading to formation of anticitrullinated protein antibodies (ACPA). Bone loss starts during this autoimmune phase due to activation of osteoclastogenesis by ACPA. A second hit (such as an infectious event or other factors) then translates the autoimmune phase into a clinical disease, which is characterised by synovitis and symptoms following synovitis, such as pain, swelling and stiffness. Cytokines produced by synovitis further enhance bone loss. into an inflammatory joint disease characterised by synovitis (figure 5). Our data also back recent findings that ACPA positive individuals show changes in lung structure, ${ }^{28}$ which indicates that the pathological process in the RA syndrome may start at extra-articular sites long before the disease homes to joints. Whether cortical bone changes triggered by ACPA provide a link between extra-articular pathology and joint disease, however, remains speculative.

Contributors AK, MK, FF, EA, AJH, UH and KE collected and analysed the data. $S F, J R, B M$ and GS designed the study. AK and GS wrote the manuscript.

Funding This study was supported by the Deutsche Forschungsgemeinschaft (SPP1468-IMMUNOBONE), the Bundesministerium für Bildung und Forschung (BMBF; project ANCYLOSS) and the TEAM and MASTERSWITCH projects of the European Union and the IMI funded project BTCure.

Competing interests None.

Ethics approval Approval of the study from the local ethics committee and the national radiation protection agency (Bundesamt für Strahlenschutz) and obtained.

Provenance and peer review Not commissioned; externally peer reviewed.

\section{REFERENCES}

1 Mclnnes IB, Schett $\mathrm{G}$. The pathogenesis of rheumatoid arthritis. N Engl J Med 2011;365:2205-19.

2 Firestein GS. Evolving concepts of rheumatoid arthritis. Nature 2003;423:356-61.

3 Mclnnes IB, Schett G. Cytokines in the pathogenesis of rheumatoid arthritis. Nat Rev Immunol 2007;7:429-42.

4 Schett $\mathrm{G}$, Gravallese E. Bone erosion in rheumatoid arthritis: mechanisms, diagnosis and treatment. Nat Rev Rheumatol 2012;8:656-64.

5 Buckland-Wright JC, Walker SR. Incidence and size of erosions in the wrist and hand of rheumatoid patients: a quantitative microfocal radiographic study. Ann Rheum Dis 1987;46:463-7.

6 Van der Heijde DM. Joint erosions and patients with early rheumatoid arthritis. $\mathrm{Br} J$ Rheumatol 1995;34:74-8.

7 Westhovens R, Robles M, Ximenes AC, et al. Clinical efficacy and safety of abatacept in methotrexate-naive patients with early rheumatoid arthritis and poor prognostic factors. Ann Rheum Dis 2009;68:1870-7.

8 Funck-Brentano T, Etchepare F, Joulin SJ, et al. Benefits of ultrasonography in the management of early arthritis: a cross-sectional study of baseline data from the ESPOIR cohort. Rheumatology 2009;48:1515-19. 
9 Goëb V, Aegerter P, Parmar R, et al. Progression to rheumatoid arthritis in early inflammatory arthritis is associated with low IL-7 serum levels. Ann Rheum Dis 2012 Published Online First 19 Oct 2012.

10 Hetland ML, Ejbjerg B, Hørslev-Petersen K, et al. MRI bone oedema is the strongest predictor of subsequent radiographic progression in early rheumatoid arthritis. Results from a 2-year randomised controlled trial (CIMESTRA). Ann Rheum Dis 2009;68:384-90.

11 Haavardsholm EA, Bøyesen $\mathrm{P}$, Østergaard $\mathrm{M}$, et al. Magnetic resonance imaging findings in 84 patients with early rheumatoid arthritis: bone marrow oedema predicts erosive progression. Ann Rheum Dis 2008;67:794-80.

12 Bøyesen $\mathrm{P}$, Haavardsholm EA, van der Heijde $\mathrm{D}$, et al. Prediction of MRI erosive progression: a comparison of modern imaging modalities in early rheumatoid arthritis patients. Ann Rheum Dis 2011;70:176-9.

13 McQueen FM, Benton N, Crabbe J, et al. What is the fate of erosions in early rheumatoid arthritis? Tracking individual lesions using $x$ rays and magnetic resonance imaging over the first two years of disease. Ann Rheum Dis 2001;60:859-68.

14 Guler-Yuksel M, Allaart CF, Goekoop-Ruiterman YPM, et al. Changes in hand and generalised bone mineral density in patients with recent-onset rheumatoid arthritis. Ann Rheum Dis 2009;68:330-6.

15 De Rooy DPC, Kalvesten J Johan, Huizingal TWJ, et al. Loss of metacarpal bone density predicts RA development in recent-onset arthritis. Rheumatology 2012;51:1037-41.

16 Freeston JE, Garnero P, Wakefield RJ, et al. Urinary type II collagen C-terminal peptide is associated with synovitis and predicts structural bone loss in very early inflammatory arthritis. Ann Rheum Dis 2011;70:331-3.

17 Pye SR, Adams JE, Ward KA, et al. Disease activity and severity in early inflammatory arthritis predict hand cortical bone loss. Rheumatology 2010:49:1943-8.

18 Machold KP, Stamm TA, Nell VP, et al. Very recent onset rheumatoid arthritis: clinical and serological patient characteristics associated with radiographic progression over the first years of disease. Rheumatology 2007;46:342-9.

19 Bosello S, Fedele AL, Peluso G, et al. Very early rheumatoid arthritis is the major predictor of major outcomes: clinical ACR remission and radiographic non-progression. Ann Rheum Dis 2011;70:1292-5.

20 Filer A, De Pablo P, Allen G, et al. Utility of ultrasound joint counts in the prediction of rheumatoid arthritis in patients with very early synovitis. Ann Rheum Dis 2011;70:500-7.

21 Sheane BJ, Beddy $\mathrm{P}, \mathrm{O}^{\prime}$ Connor $\mathrm{M}$, et al. Targeted ultrasound of the fifth metatarsophalangeal joint in an early inflammatory arthritis cohort. Arthritis Rheum 2009:61:1004-8.

22 McQueen FM, Stewart N, Crabbe J, et al. Magnetic resonance imaging of the wrist in early rheumatoid arthritis reveals a high prevalence of erosions at four months after symptom onset. Ann Rheum Dis 1998;57:350-6.

23 Rantapää-Dahlqvist $\mathrm{S}$, de Jong BA, Berglin $\mathrm{E}$, et al. Antibodies against cyclic citrullinated peptide and IgA rheumatoid factor predict the development of rheumatoid arthritis. Arthritis Rheum 2003;48:2741-9.

24 Kraan MC, Versendaal $H$, Jonker $M$, et al. Asymptomatic synovitis precedes clinically manifest arthritis. Arthritis Rheum 1998:41:1481-8.

25 Gerlag DM, Raza K, van Baarsen LG, et al. EULAR recommendations for terminology and research in individuals at risk of rheumatoid arthritis: report from the Study Group for Risk Factors for Rheumatoid Arthritis. Ann Rheum Dis 2012;71:638-41

26 Van de Sande MG, de Hair MJ, van der Leij C, et al. Different stages of rheumatoid arthritis: features of the synovium in the preclinical phase. Ann Rheum Dis 2011;70:772-7.

27 Kuhn KA, Kulik L, Tomooka B, et al. Antibodies against citrullinated proteins enhance tissue injury in experimental autoimmune arthritis. J Clin Invest 2006:116:961-73.
28 Demoruelle MK, Weisman MH, Simonian PL, et al. Airways abnormalities and rheumatoid arthritis-related autoantibodies in subjects without arthritis: early injury or initiating site of autoimmunity? Arthritis Rheum 2012;64:1756-61.

29 Harre U, Georgess D, Bang $H$, et al. Induction of osteoclastogenesis and bone loss by human autoantibodies against citrullinated vimentin. J Clin Invest 2012;122:1791-802.

30 Stach CM, Baeuerle M, Englbrecht M, et al. Periarticular bone structure in rheumatoid arthritis patients and healthy individuals assessed by high resolution computed tomography. Arthritis Rheum 2010;62:330-9.

31 Fouque-Aubert A, Boutroy $\mathrm{S}$, Marotte $\mathrm{H}$, et al. Assessment of hand bone loss in rheumatoid arthritis by high-resolution peripheral quantitative CT. Ann Rheum Dis 2010:69:1671-6.

32 Finzel S, Rech J, Schmidt S, et al. Repair of bone erosions in rheumatoid arthritis treated with tumour necrosis factor inhibitors is based on bone apposition at the base of the erosion. Ann Rheum Dis 2011;70:1587-93.

33 Finzel S, Rech J, Schmidt S, et al. Interleukin-6 receptor blockade induces limited repair of bone erosions in rheumatoid arthritis: a micro CT study. Ann Rheum Dis 2013;72:396-400.

34 Ejbjerg B, Narvestad E, Rostrup E, et al. Magnetic resonance imaging of wrist and finger joints in healthy subjects occasionally shows changes resembling erosions and synovitis as seen in rheumatoid arthritis. Arthritis Rheum 2004;50:1097-106.

35 van Schaardenburg D, Nielen MM, Lems WF, et al. Bone metabolism is altered in preclinical rheumatoid arthritis. Ann Rheum Dis 2011;70:1173-4.

36 Nielen MM, van Schaardenburg D, Reesink HW, et al. Simultaneous development of acute phase response and autoantibodies in preclinical rheumatoid arthritis. Ann Rheum Dis 2006;65:535-7.

37 Hughes-Austin JM, Deane KD, Derber LA, et al. Multiple cytokines and chemokines are associated with rheumatoid arthritis-related autoimmunity in first-degree relatives without rheumatoid arthritis: Studies of the Aetiology of Rheumatoid Arthritis (SERA). Ann Rheum Dis 2012. Published Online First 21 August 2012.

38 Hayer S, Redlich K, Korb A, et al. Tenosynovitis and osteoclast formation as the initial preclinical changes in a murine model of inflammatory arthritis. Arthritis Rheum 2007;56:79-88.

39 Gent YY, Voskuyl AE, Kloet RW, et al. Macrophage positron emission tomography imaging as a biomarker for preclinical rheumatoid arthritis: findings of a prospective pilot study. Arthritis Rheum 2012;64:62-6.

40 Duthie JJ, Gardner DL, Richmond J, et al. Nature of anaemia in rheumatoid arthritis III. Changes in the bone marrow and their relation to other features of the disease. Ann Rheum Dis 1956:15:217-26.

41 Jimenez-Boj E, Redlich $\mathrm{K}$, Türk $B$, et al. Interaction between synovial inflammatory tissue and bone marrow in rheumatoid arthritis. J Immunol 2005;175:2579-88.

42 McQueen FM, Benton N, Perry D, et al. Bone edema scored on magnetic resonance imaging scans of the dominant carpus at presentation predicts radiographic joint damage of the hands and feet six years later in patients with rheumatoid arthritis. Arthritis Rheum 2003;48:1814-27.

43 Hoff M, Haugeberg G, Odegård S, et al. Cortical hand bone loss after 1 year in early rheumatoid arthritis predicts radiographic hand joint damage at 5-year and 10-year follow-up. Ann Rheum Dis 2009;68:324-9.

44 Marinova-Mutafchieva L, Williams RO, Funa K, et al. Inflammation is preceded by tumor necrosis factor-dependent infiltration of mesenchymal cells in experimental arthritis. Arthritis Rheum 2002;46:507-13.

45 Schett G, Firestein GS. Mr Outside and Mr Inside: classic and alternative views on the pathogenesis of rheumatoid arthritis. Ann Rheum Dis 2010;69:787-9.

46 Smolen JS, van der Heijde DM, Aletaha D, et al. Progression of radiographic joint damage in rheumatoid arthritis: independence of erosions and joint space narrowing. Ann Rheum Dis 2009;68:1535-40.

47 McQueen F, Clarke A, McHaffie A, et al. Assessment of cartilage loss at the wrist in rheumatoid arthritis using a new MRI scoring system. Ann Rheum Dis 2010:69:1971-5 


\section{Bone loss before the clinical onset of rheumatoid arthritis in subjects with anticitrullinated protein antibodies}

Arnd Kleyer, Stephanie Finzel, Jürgen Rech, Bernhard Manger, Manuel Krieter, Francesca Faustini, Elisabeth Araujo, Axel J Hueber, Ulrike Harre, Klaus Engelke and Georg Schett

Ann Rheum Dis 2014 73: 854-860 originally published online March 21, 2013

doi: 10.1136/annrheumdis-2012-202958

Updated information and services can be found at:

http://ard.bmj.com/content/73/5/854

These include:

References This article cites 45 articles, 28 of which you can access for free at: http://ard.bmj.com/content/73/5/854\#BIBL

Email alerting service

Receive free email alerts when new articles cite this article. Sign up in the box at the top right corner of the online article.

Topic Articles on similar topics can be found in the following collections

Collections

Degenerative joint disease (4622)

Musculoskeletal syndromes (4931)

Connective tissue disease (4235)

Immunology (including allergy) (5119)

Rheumatoid arthritis (3245)

\section{Notes}

To request permissions go to:

http://group.bmj.com/group/rights-licensing/permissions

To order reprints go to:

http://journals.bmj.com/cgi/reprintform

To subscribe to BMJ go to:

http://group.bmj.com/subscribe/ 